\section{JURNAL EKONOMI EFEKTIF}

ISSN : $2622-8882$, E-ISSN : 2622-9935

Jurnal Ekonomi Efektif, Vol. 3, No. 4, Juli 2021

@ Prodi Manajemen Fakultas Ekonomi Universitas

Pamulang

\title{
PENGARUH PROMOSI JABATAN TERHADAP PRESTASI KERJA KARYAWAN PADA MANULIFE INSURANCE INDONESIA CABANG SERANG BANTEN
}

\author{
Herry Sofyan \\ Sekolah Tinggi Ilmu Ekonomi Dwimulya, Serang, Banten, Indonesia \\ cepherbaren61@gmail.com*
}

Manuskrip: Juni -2021 Ditinjau: Juni -2021; Diterima: Juni-2021; Online: Juli-2021; Diterbitkan: Juli-2021

\begin{abstract}
ABSTRAK
Penelitian ini bertujuan untuk mengetahui pengaruh promosi jabatan terhadap prestasi kerja Karyawan pada Manulife Insurance Indonesia Cabang Serang Banten. Metode yang digunakan adalah explanatory research dengan sampel sebanyak 91 responden. Teknik analisis menggunakan analisis statistik dengan pengujian regresi, korelasi, determinasi dan uji hipotesis. Hasil penelitian ini variabel promosi jabatan diperoleh nilai rata-rata skor sebesar 3,431 dengan kriteria baik. Variabel prestasi kerja diperoleh nilai rata-rata skor sebesar 3,852 dengan kriteria baik. Promosi jabatan berpengaruh positif dan signifikan terhadap prestasi kerja dengan nilai persamaan regresi $\mathrm{Y}=9,510+0,845 \mathrm{X}$, dan nilai koefisien korelasi 0,786 atau memiliki tingkat hubungan yang kuat dengan nilai determinasi $61,7 \%$. Uji hipotesis diperoleh signifikansi $0,000<0,05$.
\end{abstract}

\section{Kata Kunci: Promosi Jabatan, Prestasi Kerja}

\section{ABSTRACT}

This study aims to determine the effect of promotion on employee performance at Manulife Insurance Indonesia Serang Banten Branch. The method used is explanatory research with a sample of 91 respondents. The analysis technique uses statistical analysis with regression, correlation, determination and hypothesis testing. The results of this research variable job promotion obtained an average score of 3,431 with good criteria. The work performance variable obtained an average score of 3.852 with good criteria. Promotion has a positive and significant effect on job performance with the value of the regression equation $Y$ $=9.510+0.845 \mathrm{X}$, and the value of the correlation coefficient is 0.786 or has a strong relationship with a determination value of $61.7 \%$. Hypothesis testing obtained a significance of $0.000<0.05$.

Keywords: Promotion, Job Performance 


\section{PENDAHULUAN}

\section{A. Latar Belakang}

Dalam menghadapi persaingan dunia usaha yang semakin kompetitif, perusahaan dituntut untuk dapat mengoptimalkan semua sumber daya yang dimiliki. Tidak sedikit jumlahnya para ilmuwan yang menganggap faktor-faktor produksi tersebut sama pentingnya (yang satu tidak lebih rendah dari yang lain). Di lain pihak, tidak sedikit pengusaha yang hanya menganggap penting faktor produksi modal. Walaupun sumber daya tersebut penting bagi organisasi, faktor yang menunjukkan keunggulan kompetitif potensial perusahaan adalah sumber daya manusia. Tanpa adanya sumber daya manusia yang menggerakkan faktor-faktor produksi, sumber-sumber yang dimiliki tidak akan dapat produktif.

Sumber daya manusia membuat sumber daya organisasi lainnya berjalan. Mengingat begitu vitalnya peranan sumber daya manusia dalam suatu perusahaan, sudah sepatutnya jika suatu perusahaan memperhatikan aspek-aspek kerja yang berkaitan dengan sumber daya manusia. Hal tersebut diharapkan karyawan yang memiliki motivasi kerja yang kuat merupakan keunggulan kompetitif suatu perusahaan. Pada dasarnya, perusahaan bukan saja mengharapkan karyawan yang memiliki tingkat intelejensi tinggi, tetapi yang terpenting mereka mau bekerja giat dan berkeinginan untuk mencapai hasil kerja yang optimal. Kemampuan, kecakapan, dan keterampilan karyawan tidak ada artinya bagi perusahaan tanpa adanya kerja keras.

Pengembangan sumber daya manusia merupakan cara agar dapat mempertahankan eksitensi kerja semua komponen organisasi. Sebuah organisasi harus mampu mengoptimalkan kemampuan sumber daya manusia yang dimilikinya agar pencapaian sasaran dapat terlaksana, namun hal tersebut tidaklah sederhana perlu pemahaman yang baik tentang organisasi terpakai sesuai kebutuhan, tentunya pimpinan perusahaan perlu pemahaman yang baik tentang organisasi, perlu ada strategi pengembangan yang matang agar sumber daya manusia yang dimiliki sebuah organisasi terpakai sesuai kebutuhan, tentunya pimpinan perusahaan perlu memotivasi karyawannya yaitu dengan promosi jabatan.

Masalah yang timbul adalah bahwa kebutuhan masing-masing orang berbeda satu dengan yang lain. Maka perusahaan haruslah menjadi suatu lembaga yang menyediakan kesempatan dalam pemenuhan kebutuhan bagi para pekerjanya. Seseorang cenderung bekerja dengan penuh semangat apabila promosi jabatan dapat diperolehnya dari pekerjaannya dan promosi jabatan kerja karyawan merupakan kunci pendorong moral, dan prestasi kerja karyawan dalam mendukung terwujudnya tujuan perusahaan (Hasibuan, 2011:203). Menurut Siagian (2012:169) promosi jabatan adalah pemindahan karyawan dari satu jabatan atau tempat kepada jabatan atau tempat lain yang lebih tinggi disertai tugas, tanggung jawab dan wewenang yang lebih tinggi dari jabatan yang diduduki sebelumnya.

Promosi jabatan dilaksanakan untuk mengoptimalkan sumber daya manusia yang dimiliki organisasi, selain itu promosi jabatan bertujuan untuk meregenerasi sumber daya manusia dalam organisasi demi kelangsungan organisasi. Prestasi kerja karyawan merupakan tolak ukur utama dalam pengembangan sumber daya manusia. Menurut Hasibuan (2016:105) prestasi kerja adalah suatu hasil kerja yang dicapai seseorang dalam pelaksanaan tugas - tugas yang dibebankan kepadanya yang didasarkan pada kecakapan dan ketepatan waktu. Menurut Mangkunegara (2016:67) prestasi kerja adalah hasil kerja secara kualitas dan kuantitas yang dicapai oleh seseorang karyawan dalam melaksanakan tugasnya sesuai dengan tanggung jawab yang diberikan kepadanya.

Manulife Insurance Indonesia merupakan bagian atau divisi dari perusahaan 
asuransi jiwa di Indonesia yang turut berkiprak di industri jasa dalam hal asuransi baik asuransi jwa, asuransi barang maupun pendidikan.

Masalah sumber daya manusia yang menyangkut prestasi kerja juga terjadi di Manulife Insurance Indonesia. Dalam hal ini Manulife Insurance Indonesia membagi karyawan atas pegawai dinas dalam dan pegawai dinas luar (agen). Para pegawai sangat membutuhkan prestasi kerja yang tinggi, karena dengan memiliki prestasi kerja yang tinggi, tujuan yang realitas, rencana kerja yang menyeluruh akan berjalan sesuai dengan yang diharapkan. Hal tersebut akan berdampak pada target premi yang ditentukan perusahaan dapat tercapai. Untuk mencapai target premi, ada dua kiat utama yang dijalankan.

Pertama mengedapankan kepentingan dinas di atas kepentingan pribadi. Kedua, mengadakan pertemuan rutin untuk memberikan motivasi, evaluasi dan menambah skill penjualan yang baik terutama untuk mengahadapi prospek (calon nasabah/pemegang polis) serta mensosialisasikan nota-nota dinas yang berhubungan dengan produk asuransi ataupun teknis pelaksanaannya.

Dalam hal ini peran agen Manulife Insurance Indonesia sangat vital. Pada umumnya para agen asuransi jiwa belum memiliki kualifikasi seperti yang diharapkan, ditandai dengan tingginya agen yang keluar. Dengan adanya masalah tersebut, tujuan pemberdayaan agen guna meningkatkan pendapatan premi dan pertumbuhan industri asuransi jiwa, bisa saja tidak tercapai secara optimal. Hal tersebut berkaitan dengan promosi jabatan dan prestasi kerja. Artinya, agen yang tidak termotivasi biasanya memiliki prestasi kerja yang kurang bagus dan kurang menikmati pekerjaan sehingga memutuskan berhenti atau malah diberhentikan. Hal tersebut menandakan adanya prestasi kerja agen Manulife Insurance Indonesia antara kondisi kerja dengan yang diharapkan. Hal lain yang menyebabkan prestasi kerja yang belum tercapai adalah rendahnya intensitas dalam melakukan pertemuan rutin untuk memberikan motivasi, evaluasi dan menambah skill penjualan yang baik. Masalah promosi jabatan terhadap prestasi kerja memiliki peranan penting dalam rangka memenuhi kebutuhan kepentingan perusahaan akan karyawannya untuk benar-benar mampu dan menguasai jenis-jenis pekerjaan baru tersebut.

Berdasarkan pemaparan di atas, maka penulis membuat judul penelitian :Pengaruh Promosi Jabatan Terhadap Prestasi Kerja Pada Manulife Insurance Indonesia Cabang Serang Banten"

\section{B. Rumusan Masalah}

1. Bagaimana promosi jabatan pada Manulife Insurance Indonesia Cabang Serang Banten?.

2. Bagaimana prestasi kerja pada Manulife Insurance Indonesia Cabang Serang Banten ?.

3. Adakah pengaruh antara promosi jabatan terhadap prestasi kerja pada Manulife Insurance Indonesia Cabang Serang Banten?.

\section{Tujuan Penelitian}

1. Untuk mengetahui kondisi promosi jabatan pada Manulife Insurance Indonesia Cabang Serang Banten.

2. Untuk mengetahui kondisi prestasi kerja pada Manulife Insurance Indonesia Cabang Serang Banten.

3. Untuk mengetahui pengaruh promosi jabatan terhadap prestasi kerja pada Manulife Insurance Indonesia Cabang Serang Banten. 


\section{TINJAUAN PUSTAKA}

\section{Promosi Jabatan}

Promosi jabatan merupakan salah satu dari beberapa macam pengembangan karier, mendapatkan promosi jabatan merupakan sebuah impian atau tujuan dari para pegawai karena apabila seorang pegawai mendapatkan promosi berarti dia mendapatkan balas jasa yang diberikan oleh instansi atau perusahaan atas kinerja yang telah dilakukannya. Pengertian promosi jabatan lainnya dikemukakan Hasibuan (2020:108) yaitu "Promosi berarti perpindahan dari suatu jabatan ke jabatan lain yang mempunyai status dan tanggung jawab yang lebih tinggi. Biasanya perpindahan yang lebih tinggi disertai dengan peningkatan gaji/upah lainnya, walaupun tidak selalu demikian".

\section{Prestasi Kerja}

Menurut Sutrisno (2020:152) mengemukakan prestasi kerja adalah catatan tentang hasil-hasil yang diperoleh dari fungsi-fungsi pekerjaan tertentu atau kegiatan tertentu dalam kurun waktu tertentu.

\section{METODE PENELITIAN}

\section{Populasi}

Populasi dalam penelitian ini berjumlah 91 responden Manulife Insurance Indonesia Cabang Serang Banten

\section{Sampel}

Teknik pengambilan sampling dalam penelitian ini adalah sampel jenuh, dimana semua anggota populasi dijadikan sebagai sampel. Dengan demikian sampel dalam penelitian ini sampel yang digunakan berjumlah 91 responden.

\section{Jenis Penelitian}

Jenis penelitian yang dipakai adalah asosiatif, dimana tujuannya adalah untuk mengetahui atau mencari keterhubungan antara variabel independen terhadap variabel dependennya

\section{Metode Analisis Data}

Dalam menganalisis data digunakan uji validitas, uji reliabilitas, analisis regresi linier sederhana, analisis koefisien korelasi, analisis koefisien determinasi dan pengujian hipotesis.

\section{HASIL PENELITIAN}

\section{Analisis Deskriptif}

Pada pengujian ini digunakan untuk mengetahui skor minimum dan maksimum skor tertinggi, ratting score dan standar deviasi dari masing-masing variabel. Adapun hasilnya sebagai berikut:

\section{Tabel 1. Hasil Analisis Descriptive Statistics}

Descriptive Statistics

\begin{tabular}{lr|r|r|r|r} 
& N & Minimum & Maximum & Mean & \multicolumn{1}{c}{ Std. Deviation } \\
\hline Promosi jabatan (X) & 91 & 28 & 44 & 34.31 & 3.949 \\
\hline Prestasi kerja (Y) & 91 & 29 & 49 & 38.52 & 4.249 \\
\hline Valid N (listwise) & 91 & & & & \\
\hline
\end{tabular}

Promosi jabatan diperoleh varians minimum sebesar 28 dan varians maximum 44 dengan ratting score sebesar 3,431 dengan standar deviasi 3,949. Skor ini termasuk pada rentang sakala 3,40-4,19 dengan kriteria baik atau setuju.

Prestasi kerja diperoleh varians minimum sebesar 29 dan varians maximum 49 dengan ratting score sebesar 3,852 dengan standar deviasi 4,249. Skor ini termasuk pada rentang sakala 3,40-4,19 dengan kriteria baik atau setuju. 


\section{Analisis Kuantitatif}

Pada analisis ini dimaksudkan untuk mengetahui pengaruh variabel independen terhadap variabel dependen. Adapun hasil pengujian sebagai berikut:

\section{a. Analisis Regresi Linier Sederhana}

Uji regresi ini dimaksudkan untuk mengetahui perubahan variabel dependen jika variabel independen mengalami perubahan. Adapun hasil pengujiannya sebagai berikut:

Tabel 2. Hasil Pengujian Regresi Linier Sederhana Coefficients $^{\mathrm{a}}$

Unstandardized

Coefficients

\begin{tabular}{llr|r|r|r|r}
\multicolumn{2}{l}{ Model } & \multicolumn{1}{c}{ B } & Std. Error & Beta & \multicolumn{1}{c|}{$\mathrm{t}$} & \multicolumn{1}{c}{ Sig. } \\
\hline 1 & (Constant) & 9.510 & 2.436 & & 3.904 & .000 \\
\cline { 2 - 8 } & Promosi jabatan $(\mathrm{X})$ & .845 & .071 & .786 & 11.986 & .000 \\
\hline
\end{tabular}

a. Dependent Variable: Prestasi kerja (Y)

Berdasarkan hasil pengujian pada tabel di atas, diperoleh persamaan regresi Y $=9,510+0,845 \mathrm{X}$. Dari persamaan tersebut dijelaskan sebagai berikut:

1) Konstanta sebesar 9,510 diartikan jika promosi jabatan tidak ada, maka telah terdapat nilai prestasi kerja sebesar 9,510 point.

2) Koefisien regresi promosi jabatan sebesar 0,845 , angka ini positif artinya setiap ada peningkatan promosi jabatan sebesar 0,845 point maka prestasi kerja juga akan mengalami peningkatan sebesar 0,845 point.

\section{b. Analisis Koefisien Korelasi}

Analisis koefisien korelasi dimaksudkan untuk mengetahui tingkat kekuatan hubungan dari variabel independen terhadap variabel dependen. Adapun hasil pengujian sebagai berikut:

Tabel 3. Hasil Pengujian Koefisien Korelasi Promosi jabatan Terhadap Prestasi kerja.

\section{Correlations $^{\mathrm{b}}$}

\begin{tabular}{llr|r} 
& & Promosi jabatan & $(\mathrm{X})$ \\
\hline Promosi jabatan $(\mathrm{X})$ & Pearson Correlation & 1 & Prestasi kerja (Y) \\
\cline { 2 - 4 } & Sig. (2-tailed) & & $.786^{* *}$ \\
\hline Prestasi kerja (Y) & Pearson Correlation & $.786^{* *}$ & .000 \\
\cline { 2 - 4 } & Sig. (2-tailed) & .000 & 1 \\
\hline
\end{tabular}

**. Correlation is significant at the 0.01 level (2-tailed).

b. Listwise $\mathrm{N}=91$

Berdasarkan hasil pengujian diperoleh nilai korelasi sebesar 0,786 artinya promosi jabatan memiliki hubungan yang kuat terhadap prestasi kerja.

\section{c. Analisis Koefisien Determinasi}

Analisis koefisien determinasi dimaksudkan untuk mengetahui besarnya persentase pengaruh dari variabel independen terhadap variabel dependen. Adapun hasil pengujian sebagai berikut:

Tabel 4. Hasil Pengujian Koefisien Determinasi Promosi jabatan Terhadap Prestasi kerja.

Model Summary

\begin{tabular}{l|c|cr|} 
& \multicolumn{2}{c}{ Model Summary } \\
Model & \multicolumn{2}{c}{$\begin{array}{c}\text { Adjusted R } \\
\text { Square }\end{array}$} & \multicolumn{2}{c}{$\begin{array}{c}\text { Std. Error of the } \\
\text { Estimate }\end{array}$} \\
\hline 1 & R Square & .613 & 2.643 \\
\hline a. Predictors: (Constant), Promosi jabatan $(\mathrm{X})$ & &
\end{tabular}


Berdasarkan hasil pengujian diperoleh nilai determinasi sebesar 0,617 artinya promosi jabatan memiliki kontribusi pengaruh sebesar $61,7 \%$ terhadap prestasi kerja, sedangkan sisanya sebesar 38,3\% dipengaruhi oleh faktor lain yang tidak dilakukan penelitian.

\section{d. Uji Hipotesis}

Pengujian hipotesis dengan uji t digunakan untuk mengetahui hipotesis mana yang diterima.

Rumusan hipotesis: Terdapat pengaruh yang signifikan promosi jabatan terhadap prestasi kerja.

Tabel 5. Hasil Uji Hipotesis Promosi jabatan Terhadap Prestasi kerja.

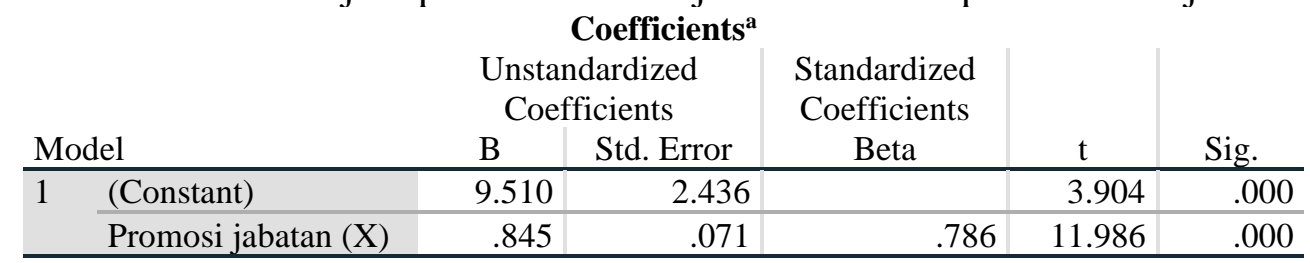

a. Dependent Variable: Prestasi kerja (Y)

Berdasarkan hasil pengujian pada tabel di atas, diperoleh nilai t hitung $>\mathrm{t}$ tabel atau $(11,986>1,987)$, dengan demikian hipotesis yang diajukan bahwa terdapat pengaruh yang signifikan atara promosi jabatan terhadap prestasi kerja diterima.

\section{Pembahasan Hasil Penelitian}

\section{Kondisi Jawaban Responden Variabel Promosi jabatan}

Berdasarkan jawaban responden, variabel promosi jabatan diperoleh ratting score sebesar 3,431 berada di rentang skala 3,40-4,19 dengan kriteria baik atau setuju.

\section{Kondisi Jawaban Responden Variabel Prestasi kerja}

Berdasarkan jawaban responden, variabel prestasi kerja diperoleh ratting score sebesar 3,852 berada di rentang skala 3,40 - 4,19 dengan kriteria baik atau setuju.

\section{Pengaruh Promosi jabatan Terhadap Prestasi kerja}

Promosi jabatan berpengaruh signifikan terhadap prestasi kerja dengan persamaan regresi $\mathrm{Y}=9,510+0,845 \mathrm{X}$, nilai korelasi sebesar 0,786 atau memiliki hubungan yang kuat dengan kontribusi pengaruh sebesar $61,7 \%$. Pengujian hipotesis diperoleh nilai thitung $>\mathrm{t}$ tabel atau $(11,986>1,987)$. Dengan demikian hipotesis yang diajukan bahwa terdapat berpengaruh signifikan antara promosi jabatan terhadap prestasi kerja diterima.

\section{KESIMPULAN DAN SARAN}

\section{Kesimpulan}

a. Variabel promosi jabatan diperoleh ratting score sebesar 3,431 berada di rentang skala 3,40 - 4,19 dengan kriteria baik atau setuju.

b. Variabel prestasi kerja diperoleh ratting score sebesar 3,852 berada di rentang skala 3,40 - 4,19 dengan kriteria baik atau setuju.

c. Promosi jabatan berpengaruh signifikan terhadap prestasi kerja dengan persamaan regresi $\mathrm{Y}=9,510+0,845 \mathrm{X}$, nilai korelasi sebesar 0,786 atau kuat dan kontribusi pengaruh sebesar $61,7 \%$ sedangkan sisanya sebesar $38,3 \%$ dipengaruhi faktor lain. Uji hipotesis diperoleh nilai $\mathrm{t}$ hitung $>\mathrm{t}$ tabel atau $(11,986>1,987)$. 


\section{Saran}

a. Dengan hasil penelitian, kejujuran karyawan mempengaruhi promosi jabatan dan perusahaan menetapkan promosi jabatan berdasarkan pengalaman.

b. Berdasarkan hasil penelitian, dengan kuantitas kerja karyawan dapat menyelesaikan pekerjaan lebih cepat dari waktu yang ditentukan, oleh karena itu karyawan konsisten dan tanggung jawab atas job description yang diberikan.

\section{DAFTAR PUSTAKA}

Algifari. (2015). “Analisis Regresi untuk Bisnis dan Ekonomi”. Yogyakarta: BPFE.

Arikunto, Suharsimi (2014). "Prosedur Penelitian Suatu Pendekatan Praktek". Jakarta: Rineka Cipta.

Edi Sutrisno (2016). Manajemen Sumber Daya Manusia. Jakarta: Prenadamedia Group.

G.R. Terry, and Rue, Leslie W. Rue (2014) Dasar-dasar Manajemen, Jakarta: Bumi Aksara.

Hasibuan, Malayu S.P. (2016). Manajemen Sumber Daya Manusia. Edisi Revisi. Jakarta: PT Bumi Aksara.

Imam Ghozali (2017). “Aplikasi Analisis Multivariate Dengan Program SPSS”. Edisi Kelima. Semarang: Badan Penerbit Undip.

Istijanto (2014) “Riset Sumber Daya Manusia”. Jakarta: PT. Gramedia Pustaka

Jasmani, J., \& Paeno, P. (2019). The Effect of Leadership and Competence on Lecturer Performance and Its Implications on Student Learning Motivation at Pamulang University. International Journal of Advances in Social and Economics, 1(4).

Mangkunegara, Prabu Anwar. (2016). Evaluasi Kinerja SDM. Cetakan ke tujuh, PT Refika Aditama: Bandung.

Nurjaya, N., et al (2021). Pengaruh Etos Kerja Dan Disiplin Kerja Terhadap Kinerja Pegawai Pada Dinas Kehutanan Dan Perkebunan Kota Bogor. JENIUS (Jurnal Ilmiah Manajemen Sumber Daya Manusia), 4(2), 172-184.

Santoso, Singgih (2015). "Menguasai Statistik Multivariat". Jakarta: PT Elex Media Komputindo.

Sareno, S. (2019). Pengaruh Kedisiplinan Terhadap Prestasi Kerja Karyawan Pada PT. Handaru Nusantara Gemilang (Dapoer Intan). JENIUS (Jurnal Ilmiah Manajemen Sumber Daya Manusia), 2(2), 244-259.

Sudjana (2014) "Metode Statistika”, Bandung: Tarsido.

Sugiyono (2017), "Metode Penelitian Administrasi : dilengkapi dengan Metode $R$ \& $D$ ". Bandung: Alfabeta.

Suryani, N. L. (2018). Pengaruh Motivasi Terhadap Prestasi Pegawai Pada Pusdiklat Tenaga Administrasi Kementerian Agama RI Ciputat-Tangerang. JENIUS (Jurnal Ilmiah Manajemen Sumber Daya Manusia), 1(3).

Wibowo (2015) Manajemen Kinerja, Jakarta: PT. Raja Grafindo Persada. 